\title{
Accurate Sea Surface heights from Sentinel-3A and Jason-3 retrackers by incorporating High-Resolution Marine Geoid and Hydrodynamic Models
}

https://doi.org/10.1515/jogs-2020-0120

Received January 14, 2021; accepted July 4, 2021

Abstract: One of the major challenges of satellite altimetry (SA) is to produce accurate sea surface heights data up to the shoreline, especially in geomorphologically complex sea areas. New advanced re-tracking methods are expected to deliver better results. This study examines the achievable accuracy of Sentinel-3A (S3A) and Jason-3 (JA3) standard retrackers (Ocean and MLE4) with that of improved retrackers adapted for coastal and sea ice conditions (ALES+ SAR for S3A and ALES+ for JA3). The validation of SA data was performed by the integration of tide gauges, hydrodynamic model and high-resolution geoid model. The geoid being a key component that links the vertical reference datum of the SA with other utilized sources. The method is tested in the eastern section of Baltic Sea. The results indicate that on average reliable sea surface height (SSH) data can be obtained 2-3 km from the coastline for S3A (for both Ocean and ALES+SAR) whilst an average distance of 7-10 $\mathrm{km}$ for JA3 (MLE4 and ALES+) with a minimum distance of 3-4 km. In terms of accuracy, the RMSE (with respect to a corrected hydrodynamic model) of S3A ALES+ SAR and Ocean retrackers based SSH were 4-5 $\mathrm{cm}$ respectively, whereas with the JA3 ALES+ and MLE4 associated SSH RMSE of 6-7 cm can be achieved. The ALES+ and ALES+ SAR retrackers show SSH improvement within a range of $0.5-1 \mathrm{~cm}$ compared to the standard retrackers. This assessment showed that the adaptation of localized retrackers for the Baltic Sea (ALES+ and ALES+SAR) produced more valid observation closer to the coast than the standard retrackers and also improved the accuracy of SSH data.
Keywords: Baltic Sea, Geoid, Tide Gauge, Hydrogeodesy, Hydrodynamic Model, Jason-3, Retracker, Satellite Altimetry, Sea Surface Height, Sentinel-3A

\section{Introduction}

Satellite altimetry (SA) is a well-known technique that is used to derive sea surface heights (SSH) both in the offshore and coastal areas. There are however some uncertainties in its' performance and obtainable SSH accuracy in near-coastal areas. The reasons for these uncertainties are mostly due to: (i) the data capture parameters (e.g. resolution, incidence angle, pulse transmission and reception techniques etc.) of different satellite missions are configured differently; (ii) specifics in retracking algorithm to determine the derived range; (iii) satellite related errors (instrumental and geophysical) that are sometimes inadequately defined and location dependent and (iv) differences that exist between the vertical reference datum of SA and other sources that is required for the accurate validation, (Slobbe et al., 2014; and Vignudelli et al., 2006).

Given that there is an increasing need for subdecimetre accuracy in SSH, especially in the near-shore area (e.g., navigation, shipping, engineering, and climate change studies) it is necessary to explore the accuracy of SA techniques especially in the coastal areas (Omstedt and Hansson, 2006). To accomplish this, data sources that serve as a reliable 'ground truth' are required. As a result,

\footnotetext{
M. Mostafavi: Department of Civil Engineering and Architecture, Tallinn University of Technology, Tallinn, Estonia, Ehitajate tee 5, Tallinn, 19086, Estonia

N. Delpeche-Ellmann: Department of Cybernetics, Tallinn University of Technology, Tallinn, Estonia

${ }^{\star}$ Corresponding Author: A. Ellmann: Department of Civil Engineering and Architecture, Tallinn University of Technology, Tallinn, Estonia, Ehitajate tee 5, Tallinn, 19086, Estonia, E-mail: artu.ellmann@taltech.ee
} 
the perspective of this study is based on validating SA accuracy using different sources and ensuring that all these data sets utilize similar vertical reference datum. Essentially the key component that enables comparison of SA data with other sources is the geoid (equipotential surface of the earth). The question now arises on the ideal source that can be used to quality control the accuracy of SA.

Traditionally SA data are validated with tide gauge (TG) records (Gomez-Enri et al., 2016; Passaro et al., 2014; Cipollini et al., 2017). Whilst this is a reasonable method, there exist two aspects that should be considered when comparing SA with TG. Firstly, TG data are mostly land bounded, as a result it represents sea level data within a particular spatial boundary of the TG location, indicating that it does not necessarily represent conditions offshore (Roemmich et al., 2017). Secondly, very often the zero level of the TG vertical reference refer to some navigational Chart Datum (e.g., mean sea level-MSL or lowest astronomic tide-LAT). These vertical datums can change from one country to another, which causes inaccuracy and compatibility issues. Given that currently many countries have implemented and are in development of a gravitybased height reference system, where the definition of vertical datum is realized through geoid modelling (e.g., NGS 2013; Véronneau and Huang 2016; Ellmann et al., 2019) it is reasonable to take advantage of such equipotential surface of the earth system. Thus, in this study we investigate the SSH accuracy that can realistically be achieved with SA through the development of a method that utilizes the geoid based vertical datum, hydrodynamic models (HDM) and TG.

Essentially, HDM-s can complement the spatial limitations of TG measurements, for they provide a reasonable estimate of sea level anywhere in the coastal and offshore areas. The only limitation is that the vertical reference used, can be with respect to their own (arbitrary) vertical reference surface, that varies both spatially and temporarily (Slobbe et al., 2014; Rulent et al., 2020; Jahanmard et al., 2021). In addition, HDM are based on a mathematical approximation that may not always be capable of simulating the exact reality of marine conditions. To overcome such limitations a solution that derives the difference between the TG and HDM at similar locations allows a vertical reference shift correction to be introduced to the HDM and thus referring to a geoid model.

Such a method has previously been explored in terms of validation of the SA derived SSH by comparison of geoid related SSH (e.g., Slobbe et al., 2014; Birgiel et al., 2018, and 2019). A similar approach is undertaken in this study, henceforth two recent satellite missions Sentinel-3A (S3A) and Jason-3 (JA3) and their associated retrackers are ex- amined in the complex coastal area of the Baltic Sea. The main difference of these two satellite altimeters is the way the transmitted and received signals are configured. For S3A can operate on both a Low-Resolution Mode (LRM) and Synthetic Aperture Radar (SAR) mode (Dinardo et al., 2020), whilst JA3 operates only at conventional pulse limited LRM. In this study the S3A SAR mode is used.

It is a common knowledge that SA measurements yield reasonable SSH results in the open sea area. The challenges remain in the coastal areas, where due to contamination of the SA signal there may be a gap (that can vary between $0-10 \mathrm{~km}$ ) on approaching the coastline (Passaro et al., 2014; Idris et al., 2020). These near coast data points are often flagged as unreliable. The gaps are located in the section of the coastal area that is commercially active and the marine dynamics are energetic and prominent. For instance, data from these gaps are of essential importance for navigation (keel clearance), marine process (breaking waves, wave set up) and marine engineering (pipeline layout, renewable energy infrastructure). One of the main reasons for this inaccurate or absence of data approaching the coastline lies in the techniques used in processing the received signal and the determination of the actual water surface level. For often on approaching the coastline the SA signals may not only be influenced by water surfaces but also by land contamination, infrastructure, turbulent waters etc.

From the return echo of the altimeter, the range ('tracking range') is usually calculated by an onboard tracker. This 'tracking range' is only a first approximation, due to noise contamination a slight misinterpretation of the actual sea surface occurs. Thus, the tracker range is usually in error and this may especially occur in coastal areas that are influenced by land, archipelagos, infrastructures etc. To compensate this error, a retracking process is utilized in a post-processing stage which attempts to fit a model response to the real waveform (Passaro et al., 2014). Implementation of the retracker results in a more accurate range determination that represents the sea surface. Altimetry however was originally designed for the open sea, thus many of these retrackers are developed (especially in the waveform modelling) for a global implementation usage that normally follow a Brown model (Brown, 1977).

In coastal areas however, where there may be other targets (e.g., land, small rocks, offshore structures, sea ice etc.) errors can be introduced that distort the shape of the received waveforms (i.e., they do not exactly conform to the Brown model). This is more prevalent to occur in the coastal areas, thus resulting in inaccuracies in the range determination. Each coastal area can also be different, thus more advanced retrackers that are specifically tuned 
to local conditions are developed (Andersen et al., 2010; Freeman and Smith, 2010). Instead, coastal waveforms have been developed based on different methods (e.g., waveform shape, multiple waveforms to detect brightest target prior to retracking, retracking of sub-waveform etc.). These advanced coastal retrackers are expected to provide better and more accurate near-coast SSH (Passaro et al., 2014; Dinardo et al., 2014; Roblou et al., 2007).

Newly developed retracking methods are expected to perform better than the standard retrackers. Monitoring their performance in coastal area is essential, as these retrackers are based on algorithms that are globally or locally tuned and may not always be applicable to a specific site. As a result, this study examines and compares standard retrackers including Ocean (for S3A) and MLE4 (for JA3) with ALES+ (for JA3) (Passaro et al., 2018) and ALES+ SAR (for S3A) (Passaro et al., 2020a and 2020b), which were developed in the framework of the European Space Agency's Sea Level Climate Change Initiative and Baltic+ SEAL projects. The intention of this study is not only to examine the overall achievable accuracy of retrackers but to take a closer examination of the retrackers' performance in the near-coastal area (i.e., $<10 \mathrm{~km}$ from the coastline).

The study site is in the Gulf of Finland located in the eastern section of the Baltic Sea. This study area is quite dynamic with its numerous archipelagos, varying coastal morphology and dynamic coastal processes. This site is exceptionally equipped with a high-density network of tide gauges that is referred to the geoid based national vertical datum. This makes an ideal study area to examine the method with assigned satellites and their retrackers. Previous studies have also examined and compared the accuracy of Sentinel-3A satellite (Birgiel et al., 2018, and 2019; Liibusk et al. 2020). In Birgiel et al., (2018) for the Sentinel3A SSH data an accuracy (root mean square error of 115 and $99 \mathrm{~mm}$ ) was achieved for the SAMOSA2 (also known as Ocean) and SAMOSA+ retrieved SSH. These retrackers however were not specifically tuned to the Baltic Sea.

Instead, one of the new aspects of this study is the utilization of a newly tuned retracker (ALES+ and ALES+ $\mathrm{SAR}$ ) that is compared to the standard retrackers (Ocean and MLE4, the SAMOSA+ dataset could also be an obvious choice to be examined, however, for brevity of this study it was excluded). The main aspects explored are: (i) quantification of how close to the coast the SA data with their different retrackers (stand alone and newly modified for the site) are able to reach the coast and the quality of these data, (ii) a closer examination of the SA derived SSH after removing a bias and (iii) examination of the accuracy of the satellites and their retrackers respect to corrected HDM.
The outline of the study is as follows. In Section 2 the developed methodology is described, whereas Section 3 contains a description of the utilized data set and study area. Section 4 describes the processing of the satellite data. In Section 5 the results are presented. A discussion of the results is presented in Section 6. A brief summary concludes the paper.

\section{Methodology}

First, interrelations between the observables and the reference surfaces used in this study are reviewed. The basic concept of satellite measurement encompasses that the satellite altimeter transmits a pulse of known power towards the sea surface. On interacting with the sea surface, the pulse is reflected to altimeter where the two-way travel time is determined, yielding the range $R_{o b s}$ of the satellite. Given the satellite altitude $h_{S A}$ with respect to reference ellipsoid (could be different for different satellite missions) the SA derived SSH is obtained (cf. Fig. 1):

$$
S S H_{S A}=h_{S A}-\left(R_{o b s}+\Delta R\right)-d h
$$

where $\Delta R$ denotes a combined correction terms (to be explained in Section 4) for the influence of the atmosphere and sea state to the SA signal. The $h_{S A}$ measurement accuracy is $1-2 \mathrm{~cm}$ benefiting from Precise Orbit Determination (POD), whereas $R_{o b s}$ is derived with a precision of a few centimetres (Normandin et al., 2018). The term $d h$ accounts for the differences of parameters in the involved reference ellipsoids, since the different SA missions and terrestrial datasets may refer to different reference ellipsoids, see Fig. 1. All terrestrial and SA datasets need to be referenced to the same reference ellipsoid using the ellipsoidal correction $(d h)$ and a local geoid model. If the SA reference ellipsoid (ellipsoid 2) differs from the one (ellipsoid 1) for terrestrial or another SA datasets, a datum conversion from different ellipsoid should be considered by using approach in (Jekeli, 2006):

$$
d h=\frac{a^{\prime}\left(1-e^{\prime 2}\right)}{\sqrt{1-e^{\prime 2} \sin ^{2} \varphi}}-\frac{a\left(1-e^{2}\right)}{\sqrt{1-e^{2} \sin ^{2} \varphi}}
$$

where $a$ and $a$ ' are lengths of the semi-major axis of participating ellipsoids, $e$ and $e$ ' are their corresponding eccentricity values and $\varphi$ is the latitude of the point of interest.

TG records and HDM data have been used to validate the $S S H_{S A}$ in this study. The TG measurements commonly refer to the zero of the national vertical datum. If the vertical datum is coinciding with an appropriate geoid model, 


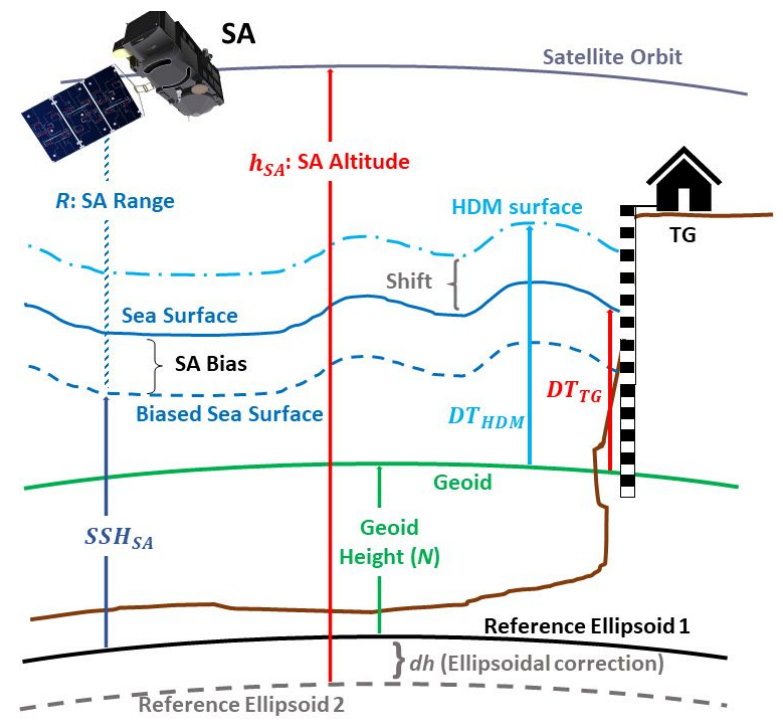

Figure 1: Interrelations between observations, data models and reference surfaces. Consult the main text body for the used symbols and abbreviations.

then the TG readings reflect the dynamic topography (DT), see Fig. 1. TG records are valid only at near-shore and may not represent adequately the offshore SSH. Conversely, a regionally computed HDM (even though referred to arbitrary vertical datum) is an independent source of offshore sea level variation. Essentially, these are equivalent to DT, but not referred to the geoid. Due to this similarity we denote the HDM derived sea level variations as $D T_{H D M}$. The HDM usually provides hourly estimation of gridded DT for a time period. $D T_{H D M}$ is a spatio-temporal function with respect to a vertical reference datum that may or may not be disclosed (idealistically it would be best to refer HDM to a regional geoid model). Due to this difference in vertical datum between TG and HDM there is a need to estimate a shift $\left(\right.$ Shift $\left._{H D M}\right)$ at nearby (say, within distance of 1-2 km, depending on the spatial resolution of HDM) TG location using:

$$
\begin{aligned}
& \operatorname{Shift}_{H D M}\left(\varphi_{T G}, \lambda_{T G}, t\right)=D T_{H D M}\left(\varphi_{T G}, \lambda_{T G}, t\right) \\
& -D T_{T G}\left(\varphi_{T G}, \lambda_{T G}, t\right)
\end{aligned}
$$

where $D T_{H D M}$ and $D T_{T G}$ are measured dynamic topography of each dataset at the location of tide gauge with $\left(\varphi_{T G}, \lambda_{T G}\right)$ coordinates. The $D T_{H D M}$ and $D T_{T G}$ series contain hourly records, whilst the SA satellite flyover occurs at a specific time. Therefore, a temporal interpolation and an approximation to the closest value is required to estimate the $D T_{T G}$ and $D T_{H D M}$ values respectively for the exact time instant $t$ of SA flyover. The Shift $t_{H D M}$ assumed to be constant spatially (along the track) and would be changed temporarily (in different cycles). This Shift $t_{H D M}$ is applied as a constant to each cell node of the HDM grid at the time of the particular SA pass. So, the TG corrected $D T_{H D M-c o r r e c t e d}$ at each HDM grid $(g)$ point could then be expressed as:

$$
\begin{aligned}
& D T_{H D M-\text { corrected }}\left(\varphi_{g}, \lambda_{g}, t\right)=D T_{H D M}\left(\varphi_{g}, \lambda_{g}, t\right) \\
& -\operatorname{Shift}_{H D M}\left(\varphi_{T G}, \lambda_{T G}, t\right)
\end{aligned}
$$

The HDM derived SSH can now be computed anywhere offshore by adding the geoidal height $N$ :

$$
\operatorname{SSH}_{H D M}\left(\varphi_{i}, \lambda_{i}, t_{i}\right)=N\left(\varphi_{i}, \lambda_{i}\right)+D T_{H D M-\text { corrected }}\left(\varphi_{i}, \lambda_{i}, t_{i}\right)
$$

where $\left(\varphi_{i}, \lambda_{i}\right)$ denotes the coordinates of an $i$-th SA trackpoint at the time $(t)$ of SA satellite flyover. For comparisons $D T_{H D M-c o r r e c t e d}$ values are interpolated both spatially and temporarily to coincide with SA track locations and simultaneous with the satellite cycles. Note that geoid models are static, i.e. lacking the time variable component. The systematic and random differences $S S H_{\text {diff }}$ of the tide gauge corrected HDM and the $S_{S S} H_{S A}$ in along-track locations $\left(\varphi_{i}, \lambda_{i}\right)$ can be determined as:

$$
\operatorname{SSH}_{\text {diff }}\left(\varphi_{i}, \lambda_{i}, t\right)=\operatorname{SSH}_{S A}\left(\varphi_{i}, \lambda_{i}, t\right)-\operatorname{SSH}_{H D M}\left(\varphi_{i}, \lambda_{i}, t\right)
$$

This provides a tentative idea of $S S H_{S A}$ accuracy, agreement to the in-situ gauge and the quality of initial SA data within the studied portion of the SA track. Here the $S S H_{H D M}$ represents ground truth in near and offshore areas. Ideally $S S H_{\text {diff }}$ should be a minimum value, still there may be outliers that can be identified by large $S_{S H} H_{\text {diff }}$ values. Usually $S S H_{S A}$ values also contain a bias (associated with each satellite track). It is of interest to investigate and eliminate such biases from $S_{S H} H_{S A}$ data-series. Thus, $S S H_{\text {diff }}$ is averaged along each track taking into consideration the number of track-points $m$ for estimating the bias

$$
\operatorname{bias}_{S A-H D M}(\operatorname{track} \#, t)=\frac{1}{m} \sum_{i=1}^{m} \operatorname{SSH}_{\text {diff }}\left(\varphi_{i}, \lambda_{i}, t\right)
$$

where $t$ shows the time of each cycle at each track number (track\#). The time instant $t$ varies (within a few seconds) in the above summation, but it can be taken as a constant for practical considerations, since $S S H_{H D M}$ has low temporal resolution (hourly estimates) and the comparisons are also spatially limited to the vicinity of the selected tide gauge. Therefore, for the sake of the brevity symbol $t$ will be used hitherto. There is an assumption that within limited spatial domain the bias is more or less constant for each cycle, whereas the bias ${ }_{S A-H D M}$ estimates may vary (e.g. due to varying atmosphere and sea state) for different cycles and tracks. Hence the bias ${ }_{S A-H D M}$ estimates need to be determined for each cycle and track. The above bias correction is implemented in the $S S H_{S A}$, yielding the corrected 
SSH estimates

$$
\begin{aligned}
& \operatorname{SSH}_{S A-\operatorname{corrected}}\left(\varphi_{i}, \lambda_{i}, t\right)=\operatorname{SSH}_{S A}\left(\varphi_{i}, \lambda_{i}, t\right) \\
& -\operatorname{bias}_{S A-H D M}(\operatorname{track\# ,t)}
\end{aligned}
$$

Caused by various interferences of the radar pulses gross errors and outliers are expected in the SA datasets, which should be corrected. Exceptional outliers at the SA alongtrack locations $\left(\varphi_{i}, \lambda_{i}\right)$ are removed, using a threshold of $\mid S S H_{\text {diff }}-$ bias $_{S A-H D M} \mid>30 \mathrm{~cm}$ (see e.g., Birgiel et al., 2019).

To evaluate the performance of the corrected $\mathrm{SSH}_{S A \text {-corrected }}$ in each cycle the post-fit residuals of the remaining $S S H_{S A \text {-corrected }}$ values and the reference $S S H_{H D M}$ data are determined by:

$$
\begin{aligned}
& \Delta S S H\left(\varphi_{i}, \lambda_{i}, t\right)=S S H_{S A-\text { corrected }}\left(\varphi_{i}, \lambda_{i}, t\right) \\
& -\operatorname{SSH}_{H D M}\left(\varphi_{i}, \lambda_{i}, t\right)
\end{aligned}
$$

The root mean square error (RMSE) of post-fit residuals at each track and cycle is then estimated by:

$$
R M S E(\text { track\#, } t)=\sqrt{\frac{1}{n} \sum_{j=1}^{n}\left(\Delta S S H_{j}\left(\varphi_{i}, \lambda_{i}\right)\right)^{2}}
$$

where $n$ is the number of good quality SA points of at each cycle within the studied track portion, the sub-index $j$ is summation counter. Eq. (10) provides a statistically meaningful estimate of the accuracy of $\mathrm{SSH}_{S A}$ within the studied track portion in the given cycle.

These RMSE (track\#,t) values can be used for computing annual RMSE using all available cycles for the given track portion by:

$$
R M S E_{\text {yearly }}(\text { track\# })=\sqrt{\frac{1}{k} \sum_{i=1}^{k}(R M S E(\text { track } \#, i=t))^{2}}
$$

where $k$ is the number of available cycles per year (poor quality cycles with large number of outliers have been excluded). Along the coast these steps were repeated for all available tracks that a tide gauge station existed close to the satellite pass for each SA mission. Similarly, seasonal statistical estimates can be computed which could help to understand the behavior of bias during different meteorological conditions and to model the bias during different seasons e.g., for the sea-ice conditions. The developed method is tested and applied at 4 stations (for 6 different tracks) in the Gulf of Finland study area.

\section{Study area and used datasets}

\subsection{Study area}

The Baltic Sea (BS) is a semi-enclosed brackish water body located in northern Europe (see Fig. 2). This sea area is surrounded by nine countries, there exists a high density of marine traffic and coastal activities. The sea area is further subdivided into several sub-basins. The study site is the Gulf of Finland which is located in the easternmost section of the BS, it is a narrow and elongated marine area with a length of approximately $400 \mathrm{~km}$ and width varying from $48-135 \mathrm{~km}$. The mean water depth is around $37 \mathrm{~m}$ (maximum depth is $123 \mathrm{~m}$ ).

The short-term sea level dynamics in the gulf are affected by changes in the water balance that are mostly driven by atmospheric conditions (e.g. winds direction), river runoff and the presence of sea ice. Localised events (e.g. storm surges, coastal upwellings, see e.g. DelpecheEllmann et al., 2017 etc.) shall also affect the short term and seasonal variability. Due to the prevailing south-west wind direction, storminess and river discharge (the Neva river, located on the eastern end is the largest contributor of fresh water in the Baltic Sea) a higher MSL and extreme water levels tends to occur on the eastern section. For instance, the mean sea surface topography (averaged from 2014-2019) increases eastwards in the gulf from 20 to 29 $\mathrm{cm}$ (Kollo and Ellmann, 2019). The typical significant wave height is within the range of $0.5-0.8 \mathrm{~m}$, with a maximum significant wave height of $5.2 \mathrm{~m}$ (Soomere et al., 2008).

The gulf is surrounded by Finland to the north, Estonia to the south and Russia to the east. The geomorphology of the coastline can be cliff like or low-lying with indented coastlines and peninsulas present. The coastal area is characterised by several archipelagos, small islands, and rocks within $10 \mathrm{~km}$ from the coastline. The gulf is equipped with the presence of precise and dense TG network and high quality geodetic infrastructure. The above characteristics make the gulf an ideal site to evaluate the performance of SA in the coastal area.

Two recent satellite missions S3A, JA3 and their associated retrackers are examined in this complex coastal area. For this, the along-track $S S H_{S A}$ data are examined and compared with the $S S H_{H D M}$ data at four operational tide gauge stations including: Narva-Jõesuu, Kunda, Loksa and Paldiski, see Fig. 2. The selected data period of all available cycles is one year, from January to December 2017, considering that 2017 is the first full year period for both examined satellites. The presence of sea ice tends to be a challenge for SA in determining accurate SSH. For 2017 sea ice 
conditions were mild with most of the fast ice concentrated on the extreme eastern section of the gulf and around the western large islands (Hiiumaa and Saaremaa) off the Estonian coast.

\subsection{Geoid model: EST-GEOID2017}

This study uses a recent high-resolution Estonian quasigeoid EST-GEOID2017 model (Ellmann et al., 2019), which covers the region from $57^{\circ} \mathrm{N}$ to $60^{\circ} \mathrm{N}$ latitude and from $20^{\circ} \mathrm{E}$ to $30^{\circ} \mathrm{E}$ longitude, with a spatial resolution of $0.01^{\circ} \times$ $0.02^{\circ}(1.8 \times 1.8 \mathrm{~km})$. The extent of the model also sets geographical limitations to other datasets. Hence no SA data were examined beyond the northern boundary $\left(60^{\circ} \mathrm{N}\right)$ of the geoid model. Additional input data (gravity data and elevation models from neighboring countries) were obtained through participating in the Nordic-Baltic joint geoid modelling project NKG2015 (Ågren et al., 2016; Märdla et al., 2017). Using a set of high-precise GNSS levelling points the geoid model is fitted to the Estonian vertical datum EH2000, which is the national realization of the European Vertical Reference System-EVRS (the zero of which is the Normaal Amsterdams Peil - NAP). The ESTGEOID2017 geoid model is an official part of the Estonian vertical datum, hence the model is used to convert GNSSderived ellipsoidal heights to EH2000 heights and vice versa. Also the tide gauge records yield the $D T_{T G}$ values that are referred to the EST-GEOID2017 model. The geoid model accuracy on land is estimated to be $5 \mathrm{~mm}$ (Ellmann et al., 2019), the geoidal heights are given with respect to the GRS80 ellipsoid.

\subsection{Hydrodynamic Model: HBM-EST}

The three-dimensional baroclinic eddy-resolving circulation model HIROMB-Boost Hydrodynamic Model (HBMEST) developed by the Marine Systems Institute (Lagemaa et al., 2011) and specially tuned to the Estonian waters was implemented in this study for evaluating along-track performance of SA data. The horizontal resolution of the model is of 0.5 nautical miles. This model is divided into 50 vertical layers, with the thickness of each layer $4 \mathrm{~m}$ in the upper $80 \mathrm{~m}$. The temporal resolution of the model is one hour. The open boundary of the HBM-EST model is located at the Danish Straits, i.e. the western edge of the Baltic Sea. The atmospheric forcings are sourced by the highresolution limited area model (HIRLAM) and the daily data from the river runoff model HBV (Hydrologiska Byråns Vattenbalansavdelning) is used for freshwater inflow. Sea ice data was obtained from Louvain-la-Neuve sea ice model (LIM3). The HBM-EST model is currently used mostly for operational sea level forecast in Estonia and plays a crucial role in the short-term prediction of the sea level. The model data provides $D T_{H D M}$ and could be used as an independent source for the offshore. The HDM vertical reference datum is undisclosed thus there is a need to obtain the $\operatorname{Shift}_{H D M}(\mathrm{Eq}$. 3) by using tide gauge measurements to derive $D T_{H D M}$ from the HDM sea level. This model covers a region from $57^{\circ} \mathrm{N}$ to $60^{\circ} \mathrm{N}$ latitude and from $21^{\circ} \mathrm{E}$ to $30^{\circ} \mathrm{E}$ longitude, spatial resolution of $0.008^{\circ} \times 0.016^{\circ}(529 \times$ 455 horizontal grid points) (Lagemaa, 2012). The HBM-EST data was retrieved from http://emis.msi.ttu.ee.

\subsection{Tide gauge data and nearby SA tracks}

Within the study area there are four Estonian TG stations which have suitable location nearby satellites' tracks (see Fig. 2 and Table 1). The tide gauge network is operated by the Estonian Environment Agency. Sea level data $\left(D T_{T G}\right)$ are recorded hourly and the measurements are referred (following methodology in Kollo and Ellmann, 2019) to the geoid based vertical datum EH2000. The zero of the utilized Estonian TG stations coincide with a recent highresolution geoid model EST-GEOID2017 (Ellmann et al., 2019) and necessary corrections applied including vertical land motion and TG sensor drift correction (Kollo and Ellmann, 2019).

The first full year cycle after launch of the Sentinel-3A and Jason-3 satellites occurred in 2017, so the first 2017 cycle for the S3A and JA3 satellites is numbered 13 and 33, respectively. Table 1 contains the used TG stations and their related SA track number (both ascending and descending passes) of each SA mission.

\subsection{Satellite altimetry missions}

Two satellite missions are examined in this study: Sentinel- 3A operating in Synthetic-aperture radar (SAR) mode and Jason 3 that operates in Low Resolution Mode (LRM). In SAR mode the transmit signals are sent in bursts that exploits an inter burst interval to receive the reflected pulses, whilst in the LRM the transmit and receive signals are processed incoherently. In SAR mode it is expected that a noise reduction and a finer along track resolution due to the acquisition of the high-rate digitized burst pulses (Dinardo, 2020). The main SA elements are explained below. 

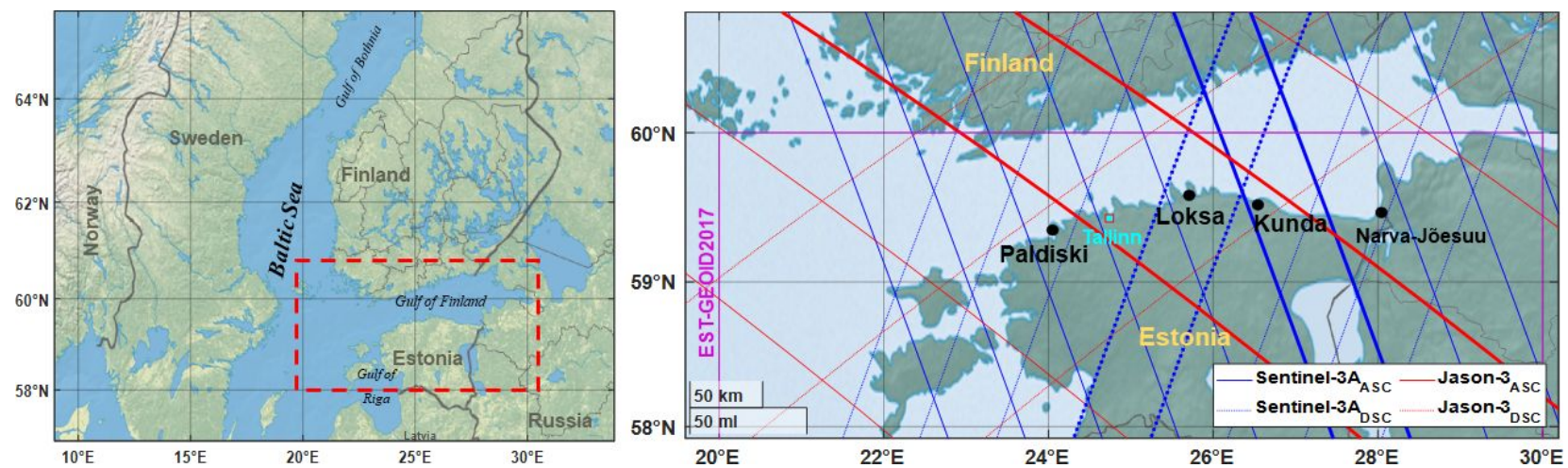

Figure 2: Location of the study area in Baltic Sea (left) and the JA3 (red) and S3A (blue) satellite tracks (used tracks are in bold) and location of tide gauge stations (black dots) in Gulf of Finland (right).

Table 1: List of TG used stations and nearby SA tracks, see Fig. 2 for their exact locations.

\begin{tabular}{|c|c|c|c|c|c|c|}
\hline TG station Name & LAT $\left[{ }^{\circ}\right]$ & $\operatorname{LON}\left[{ }^{\circ}\right]$ & Satellite & $\begin{array}{c}\text { Pass\# } \\
\text { (asc/desc) }\end{array}$ & $\begin{array}{l}\text { Cycles } \\
(2017)\end{array}$ & $\begin{array}{c}\text { Distance to TG } \\
\text { [KM] }\end{array}$ \\
\hline Kunda & 59.521 & 26.542 & \multirow{3}{*}{ S3A } & $083^{\star} / 414$ & $13-26$ & $9 / 14$ \\
\hline Loksa & 59.584 & 25.707 & & $739 / 300$ & $13-25$ & $-/ 17$ \\
\hline Narva-Jõesuu & 59.469 & 28.042 & & $197 / 528$ & $13-25$ & $38 /-$ \\
\hline Paldiski & 59.351 & 24.049 & \multirow{2}{*}{ JA3 } & $16 /-$ & $34-69$ & $19 /-$ \\
\hline Kunda & 59.521 & 26.542 & & 92 / - & $33-68$ & $15 /-$ \\
\hline
\end{tabular}

\subsubsection{Sentinel-3A}

Sentinel-3A was launched in February 2016 and apart from a Synthetic Aperture Radar Altimeter (SRAL), it is also equipped some other sensors (e.g., ocean and land color instrument, DORIS system, laser retroreflector, microwave radiometer amongst others). SRAL is the first dual frequency (Ku/C-bands, 13.575 and $5.41 \mathrm{GHz}$, respectively) near-nadir radar altimeter that operates fully in SAR mode. To achieve correlated pulses, the SAR altimeter emits 64 pulses towards the sea surface at a pulse repetition frequency of $17.8 \mathrm{kHz}$. A fast Fourier transform is performed on the received pulses in the along-track dimension, generating 64 Doppler footprints. The corresponding footprint shape is more rectangular shape than a round shape, for more details see Table 1 . The echoes reflected from these Doppler footprints are averaged to generate multi-looked SAR waveforms. The European Organisation for the Exploitation of Meteorological Satellites (EUMETSAT) processes and distributes marine data. Reprocessed standard data can be downloaded from EUMETSAT Earth Observation Portal https://eoportal.eumetsat.int/. The Non-Time Critical (NTC) $20 \mathrm{~Hz}$ range values containing standard "Ocean" retracker with geophysical and environmental correction estimates were extracted to compute the $S S H_{S A}$.

\subsubsection{Jason-3}

The satellite was launched in January 2016, is a follow-on altimetry mission of TOPEX/Poseidon (T/P), Jason-1 and Jason-2, with the same repeat orbit (9.9156 days) as its predecessors. The Jason-3 onboard nadir-looking Posideon3B altimeter is a dual-frequency $(\mathrm{Ku} / \mathrm{C}$ bands, 13.575 and $5.3 \mathrm{GHz}$, respectively), which is capable to mapping the sea surface topography with high reliability. This pulselimited altimeter operates in LRM over the global ocean. The along track horizontal resolution of $\sim 300 \mathrm{~m}$ is attainable, and the footprint shape is circle like. In this study, we use the official Geophysical Data Record (GDR) $20 \mathrm{~Hz}$ data product containing standard "MLE4" retracker, which can be accessed from a dedicated AVISO+ FTP server on ftp://ftp-access.aviso.altimetry.fr/.

\subsection{Satellite Altimetry Retrackers}

Many of the developed SA retrackers represent a global implementation with the reflected waveform normally following a Brown model (Brown, 1977) that conforms to the open ocean. The waveform for this model is usually characterized by fast-rising leading edge and a slowly decaying trailing edge. The echo's leading edge signifies the parameters of importance for the re-tracking (epoch, significant 
Table 2: The used SA mission's specifications

\begin{tabular}{|c|c|c|c|c|c|c|c|}
\hline Mission & Altimeter & Mode & $\begin{array}{c}\text { Altitude } \\
\text { [km] }\end{array}$ & Inclination & $\begin{array}{c}\text { Cycle period } \\
\text { [Days] }\end{array}$ & $\begin{array}{c}\text { Along-track } \\
\text { resolution }\end{array}$ & $\begin{array}{c}\text { Across-track } \\
\text { resolution }\end{array}$ \\
\hline Sentinel-3A & SRAL & SAR & 814.5 & $98.65^{\circ}$ & 27 & $\sim 300 \mathrm{~m}$ & 1.64 km \\
\hline Jason-3 & Poseidon-3B & LRM & 1336 & $66.04^{\circ}$ & 9.91 & $\sim 300 \mathrm{~m}$ & 10 km* \\
\hline
\end{tabular}

wave height, backscatter coefficient). A specific point on the leading edge, known as the retracking point, is used to mark the point of measurement of altimeter vertical range to surface. In non-ocean areas though, altimetry suffers the distortion in waveforms, consequently, the waveform deviates from its standard shape. Therefore, there is a need to correct the distorted waveform. The difference of mid-point on the leading-edge respect to the nominal gate (in terms of gate number) represents an estimate of the retracking correction. New coastal SA retrackers are expected to improve the quality SA data by considering all these aspects.

As a result, this study compares the JA3 and S3A standard products using "MLE- 4 " and "Ocean" retrackers with that of improved retrackers (ALES+ for JA3 and ALES+SAR for S3A) that are specifically adjusted for coastal and sea ice conditions of the Baltic Sea. The retrackers data have been assessed for time period of 2017 in this study.

\subsubsection{Ocean Standard Retracker}

The SAMOSA (SAR Altimetry MOde Studies and Applications) is a physical, full SAR (Synthetic Aperture Radar) waveform retracker that was developed for open-ocean waters (Dinardo et al., 2014). It extracts from the return power waveform (echo) the ocean geophysical information in a non-linear curve best scheme, based on a bounded Levenberg-Marquardt Least-Squares Estimation Model (LEVMAR-LSE). SAMOSA retracker provides a closed-analytical expression of the waveform and exists in different versions. Improved "Ocean like" (Ocean) retracker (SAMOSA V2.5) is one of the standard retracker available in level-2 datasets of Sentinel-3A SRAL altimeter (Ray et al., 2015).

\subsubsection{MLE4 Standard Retracker}

The MLE4 retracker is based on a 2nd order Brown analytical model and is based on the Hayne model (Hayne, 1980). It estimates the four parameters (range, significant wave height, power of the trailing edge Sigma0) by determin- ing the value that maximizes the probability of obtaining the recorded waveform shape in the presence of noise of a given statistical distribution (Thibaut et al., 2006). The MLE4 algorithm performing very well for mispointing angles up to 0.8 degrees and significantly improved in range estimation especially in areas where altimeter waveforms present a typical trailing edge slopes comparing to MLE3 retracker (Thibaut et al., 2010). In this study we used the GDR product $20 \mathrm{~Hz}$ available in level 2 products which can be accessed from a dedicated AVISO+ (Archiving Validation and Interpretation of Satellite Oceanographic) FTP server on $\mathrm{ftp}$ ://ftp-access.aviso.altimetry.fr/.

\subsubsection{Baltic Sea Adapted Retracker ALES+ and ALES+SAR}

The Baltic+SEAL consists of a novel improved multimission sea level data product for the Baltic Sea (BS). The retrackers employed for the data products consists of ALES+ which was utilized for the LRM altimeter and ALES+SAR for the delayed Doppler altimeters (Passaro et al., 2020a). In this study the high frequency along-track altimetry SSH of Baltic+SEAL data have been utilized.

ALES+ is a modification of ALES (Adaptive Leading Edge Sub-waveform) which is based on the Brown-Hayne functional form that models the radar returns from the ocean to the satellite. It is based on a sub-waveform retracker that adapts the fitting of the signal depending on the sea state and on the slope of its trailing edge (Passaro et al., 2018; 2020a). The sea state bias correction is deduced by means of statistical techniques based on the observations using high frequency wind speed and significant wave height (SWH) estimates from ALES+ (refer to Passaro et al., 2020a for more details). ALES+SAR is utilized for the delayed Doppler altimeters and this adopts a simplified version of the Brown-Hayne functional form as an empirical retracker to track the leading edge of the waveform. The different values between ALES+ and ALES+SAR is due to the different signal to noise ratio of the LRM mode vs SAR (refer to Passaro et al., 2020a for more details).

In this study the SSH data has been extracted from the Baltic+SEAL Sentinel-3A (ALES+SAR) and Jason-3 
(ALES+) $20 \mathrm{~Hz}$ products. The data was obtained from http://balticseal.eu/data-access/.

\section{Data processing}

The $S_{S H} H_{S A}$ data for S3A Ocean and JA3 MLE4 retrackers were directly derived by Eq. 1. Where the standard atmospheric and geophysical corrections applied for the Ocean and MLE4 retrackers are displayed below:

\section{$\Delta R=$ ionospheric correction}

+ dry tropospheric correction

+ wet tropospheric correction + sea state bias

+ ocean tide + load tide + pole tide + solid earth tide

$\Delta R_{A L E S+}=$ ionospheric correction

+ dry tropospheric correction

+ wet tropospheric correction + sea state bias

+ ocean tide + load tide + pole tide + solid earth tide

+ dynamic atmosphere correction

+ radial orbit correction

For Baltic+SEAL datasets (ALES+ and ALES+SAR) the $S S H_{S A}$ data were directly extracted from the database. Whilst the basic formulae for $S S H_{S A}$ remains the same (Eq. 1) the standard atmospheric and geophysical corrections utilized slightly varied. Eq. 13 displays two additional corrections, Dynamic Atmosphere Correction (DAC) and Radial Orbit Errors (ROC) that were applied to the Baltic+SEAL dataset. Note that the ocean tide and load tide (summarized and stored as one value) is not included in the extracted Baltic+SEAL SSH but was applied afterwards in our calculations.

The $S_{S H} H_{S A}$ from Baltic+SEAL products and the Jason3 standard products refer to the T/P reference ellipsoid, while $S S H_{H D M}$ model data refers to GRS80. The vertical height difference between two ellipsoids need to be applied to SA dataset to relate them to the same ellipsoid. Therefore, a difference between the ellipsoids of T/P and GRS80 in Baltic Sea needs to be accounted for. The corresponding ellipsoidal correction was determined by inserting into Eq. 2, where $a_{T / P}=6378136.3$ $\mathrm{m}, e_{T / P}=0.081819221456 \mathrm{~m}$ and $a_{G R S 80}=6378137.0 \mathrm{~m}$, $e_{G R S 80}=0.081819190842621$, yielding $d h=72.6 \mathrm{~cm}$. This correction was applied to $S S H_{S A}$ derived by MLE4, ALES+ and ALES+SAR retrackers. The Sentinel-3A derived $S S H_{S A}$ (standard product) reference ellipsoid is WGS84. The sub- $\mathrm{mm}$ range difference between GRS80 and WGS84 geometry can be neglected in this exercise. The different datasets were processed using the developed method to validate the retrackers performance against the ground truth. As TG and HDM provide hourly data, the closest data to the satellite overfly time have been selected which could represent the best sea condition at that time. For S3A the standard Ocean retracker for cycle 13-26 and MLE4 retracker of JA3 was employed for cycles 33-69 in the year 2017. Figure 3 shows the flowchart of the entire data processing.

\section{Results}

Examination of both Sentinel-3A and Jason-3 SA alongtrack data cycles using the various retrackers (Ocean, MLE4, ALES+, ALES+SAR) for 2017 represented some interesting characteristics with respect to: (i) along-track performance in terms of quantity and quality of satellite data on approaching the near-coast, (ii) bias consistency/inconsistency and (iii) the overall accuracy of the satellite and their retrackers.

\subsection{Along-track performance of $\mathrm{SSH}_{S A}$}

Investigation of the satellites' cycles along track data points using the different retrackers showed disparity with respect to how close to coast useful $S S H_{S A}$ data was retrievable (cf. Table 3).

To obtain the best quality and quantity of data points in the near-coast areas for each dataset all the data points up to the coastline were first examined. This was followed by the removal of obvious outliers by using a predefined threshold of a difference between $S_{S S} H_{S A \text {-corrected }}$ and $S S H_{H D M}$ larger than $30 \mathrm{~cm}$ (see $\mathrm{Sec}$ 2). Baltic+SEAL official quality flags are also available, which in future studies is an option to be explored further.

Table 3 shows the average distance from the first available data point to the nearest coastline (after the removal of obvious outliers). As both datasets (Level-2 and Baltic+SEAL) provide same points location along a track, distance to the coast is measured respect to a single point to the coast. Since the distance varies for each cycle the minimum distance that was observed is also shown. Note that this distance does not necessarily represent minimum along track distance to the coast. Instead it depends on the shape and configuration of the coastline and its closeness to the satellite track. 


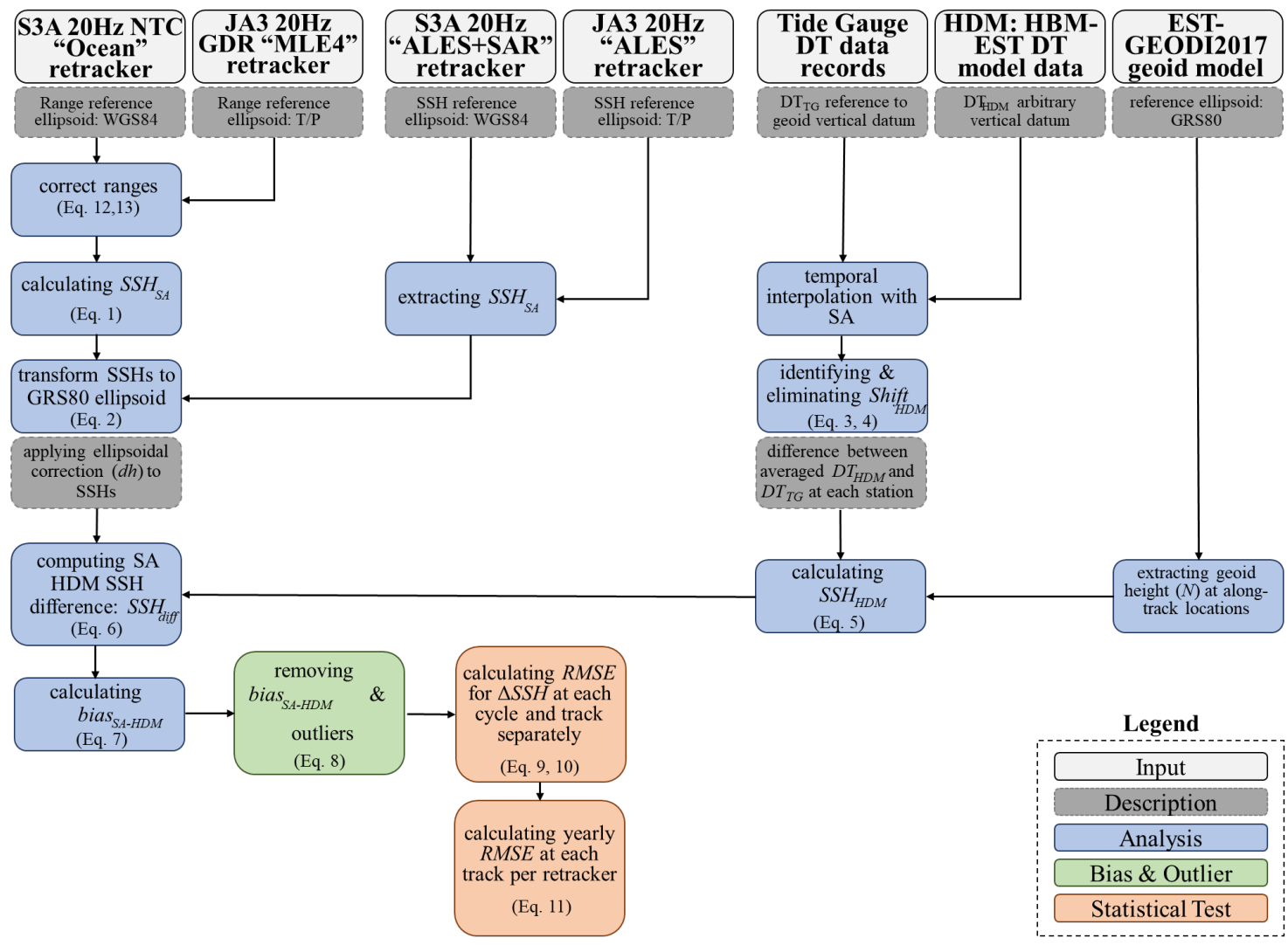

Figure 3: Flowchart of different stages of the developed method for validating the satellite altimetry retracker.
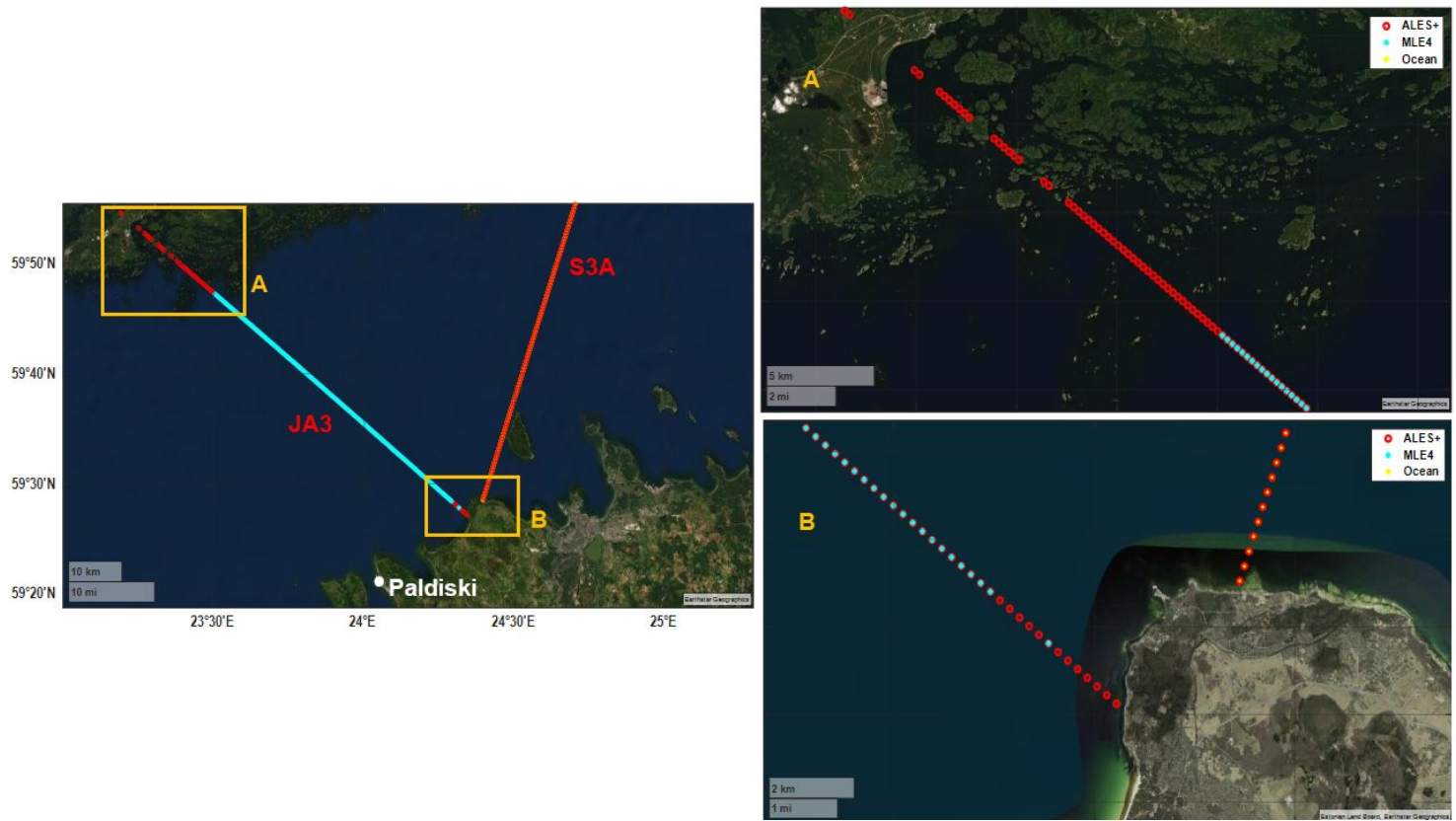

Figure 4: Locations of the near-coast SA tracks: the S3A (pass\#186 cycle 13) and JA3 (pass\#016 cycle 34) tracks performance near the shoreline at Paldiski station (left hand side). The JA3 track (A) performance using ALES+ (red) and MLE4 (blue) retrackers, zoom in near the Finnish coast; and the JA3 and S3A tracks (B) performance using ALES+ and ALES+SAR (red), Ocean (yellow) and MLE4 (blue) retrackers near the Estonian coast (right hand side).

The coastline source is the Google Earth. 
Table 3: Average and minimum distances from the first valid SA data point to the nearest coastline ( $\mathrm{km})$ after removing outlier data, for each satellite track.

\begin{tabular}{ccccccc}
\hline Pass Number & \multicolumn{2}{c}{ Average Distance $[\mathrm{km}]$} & \multicolumn{2}{c}{ Minimum Distance $[\mathrm{km}]$} & \multicolumn{2}{c}{ Average no. of Outliers } \\
\hline Sentinel-3A & Ocean & ALES+ SAR & Ocean & ALES+ SAR & Ocean & ALES+ SAR \\
\hline Kunda\#083 & 2.77 & 2.95 & 2.02 & 2.02 & 17 & 13 \\
Kunda\#414 & 2.07 & 2.07 & 1.73 & 1.73 & 7 & 5 \\
Loksa\#300 & 2.32 & 2.57 & 1.93 & 1.93 & 9 & 4 \\
Narva-Jõesuu & 2.74 & 2.74 & 2.47 & 2.47 & 12 & 12 \\
\#197 & MLE4 & ALES+ & MLE4 & ALES+ & MLE4 & ALES+ \\
\hline Jason-3 & 9.87 & 3.99 & 3.29 & 3.58 & 8 & 3 \\
\hline Kunda\#092 & 9.87 & 2.99 & 2.54 & 4 & 3 \\
Paldiski\#016 & 6.62 & 6.72 & &
\end{tabular}

The results display that valid JA3-MLE4 retracker data points were obtained on average for $7-10 \mathrm{~km}$ from the coastline, with the minimum distance of data points reaching as close as $3-4 \mathrm{~km}$ from the coastline. An example of this is illustrated for the Paldiski station (Fig. 4 left hand side; at location $\mathrm{A}$ and $\mathrm{B}$ ), in terms of quantity of data points that approached the coast. For in Fig. 4-B for JA3 (pass\#16 cycle\#34) ALES+ provide 12 more data points that accounted for the $4 \mathrm{~km}$ longer stretch than the MLE4 retracker. Also, in the Finnish archipelago (Fig. 4-A right hand side) it is obvious that many MLE4 data points (around 47 points) have been removed as they have been detected as outliers. Conversely, in the ALES+ retracker (in JA3 mission) they are available for possible examination, if required. Thus ALES+ provided the most reliable data up to the coast for JA3, as compared to the MLE4 retracker after removing obvious outliers.

On the contrary, the S3A (the Ocean and ALES+ SAR retrackers) consistently provided data points on average 2-3 $\mathrm{km}$ from the coast (see Fig. 5), with very little difference between retrackers. An example is illustrated in Table 3 and Fig. 4 (bottom) for Kunda station that shows whilst data points increased closer to the coast with ALES+ SAR, the actual distance to the coast was the same for the Ocean retracker. This may be due to the similarities that exist between the Ocean and ALES+ SAR retrackers. Thus, comparison between JA3 and S3A shows that a bigger difference was observed in the JA3 satellite using ALES+ (as compared with MLE4) which showed more data points closer to the coast.

Regarding the closeness to the coast S3A performed better than JA3. This may be due to the capabilities of S3A SAR mode where the pulses are transmitted and received with a higher PRF (pulse repetition frequency) and the inter-burst interval that allows a finer resolution and less noisier data (Dinardo, 2020) compared to the JA3 associated LRM. This highlights some of the essential benefits

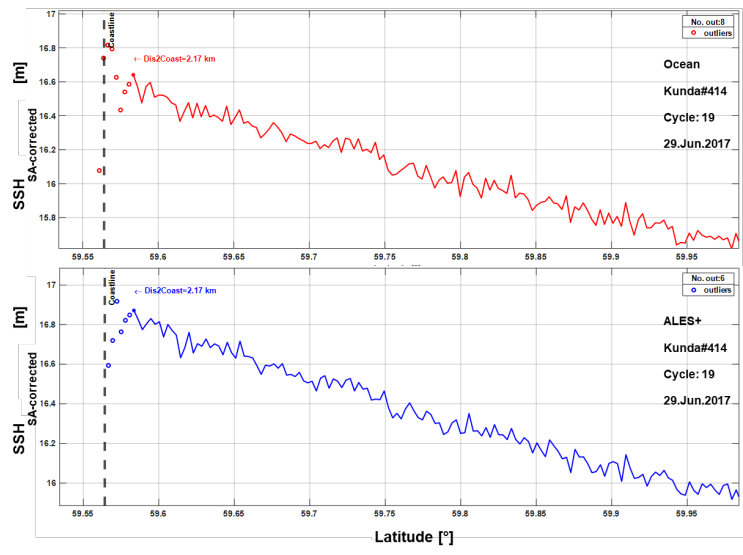

Figure 5: The along track $S S H_{S A}$ at Kunda station, pass \#414 using Ocean (red) and ALES+ SAR (blue) retrackers and detected outliers (circles). Distance to the coast from first available good quality point is measured. The vertical dashed line denotes the location of coastline. The colored circles denote near-coast $S S H_{S A}$.

of the SAR mode. Considering that the different satellites used different orbits and inclination, their ground track are expected to differ. Thus, the shape of the coastline and the presence of numerous small islands/archipelagos differ for individual satellites' track. This would influence the quality, number of data points retrieved and the distance to the coastline.

The question now remains on whether the increased amount of the retracker data points actually provided valid data points. Figure 6 shows for each retracker/mission using all available cycles in 2017 at Kunda station the along-track discrepancies (before any obvious outlier removal). In general it is obvious that better coherence was provided by the ALES+ and ALES+SAR retracker (compared to the Ocean and MLE4 ones). This is also reflected in Table 4 which showed smaller RMSE estimates for the ALES+ and ALES+ SAR retracker. Thus 
the retracking algorithms and corrections used in the Baltic+SEAL datasets makes a difference in the quality and quantity of data on the near coast area. As a result, the usage of a coastal retracker appears relevant and applicable for the Baltic Sea area.

Closer examination of the critical areas (approaching the near-coast/shoreline) shows that for some cycles within the $0-10 \mathrm{~km}$ zone a larger $S S H_{\text {diff }}$ are present. For example, in Fig. 6 for S3A $S S H_{S A}$ data at Kunda station, the noisiest section appears to be within the first $10 \mathrm{~km}$. On most occasions these larger values occur for particular cycles, this suggest that problems may not only be related to land contamination. Instead it is highly likely to be due to the marine dynamics, atmospheric and geophysical corrections applied, at these locations for particular instances in time. In this section of the near coast area various marine processes (e.g. breaking surface waves, upwellings etc.) may affect not only the sea state but also the atmosphere.

Interestingly for some cycles largest differences were not confined only to the nearshore but instead in some problematic cycles the entire track was affected. For instance, S3A cycle 18 of both ALES+ SAR and Ocean retrackers at Kunda station (pass\#083) on $21^{\text {st }}$ May 2017 (Fig. 6). This may be due to degradation of range/geophysical corrections, waveform contamination by land and bright targets, or perhaps sea state at this particular time.

\subsection{Bias correction}

By utilising $D T_{H D M}$ and the geoid model the $S S H_{H D M}$ estimates were computed by Eq. (5). $S S H_{H D M}$ is considered as the 'approximate true' value. This calculation allows us to validate the $S S H_{S A}$ data with the $S S H_{H D M}$. Note that all the relevant data sources are now referenced to the same reference ellipsoid of GRS80. Figure 7 displays an example of these results at the Kunda and Narva-Jõesuu stations. Figure 7 reveals that between the $S S H_{S A}$ and $S S H_{H D M}$ datasets a $S S H_{\text {diff }}$ exist and this $S S H_{\text {diff }}$ changes with time and location. The quantification of $S_{S} H_{\text {diff }}$ allows a bias estimate (Eq. 7) to be applied to the $S S H_{S A}$. Once the bias $_{S A-H D M}$ is implemented a reasonable agreement between the $S S H_{S A}$ and the $S S H_{H D M}$ is present. In Fig. 7 the

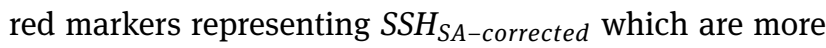
comparable to $S_{S H} H_{H D M}$.

The bias ${ }_{S A-H D M}$ are presented for each station using the different missions and their retrackers (Fig. 8). In theory the bias is expected to be at a minimum, however, from Fig. 6 to 8 it is quite obvious that the bias changes randomly. Inspection of the bias with respect to the ground truth (Table 4) shows that with the S3A Ocean data, the bias can vary maximum from -70.2 to $+49.3 \mathrm{~cm}$ (a mean of 18.6 to $20.6 \mathrm{~cm}$ ) whilst for S3A-ALES+SAR data it varied from -19.2 to $39.4 \mathrm{~cm}$ (a mean of 9.3 to $13.4 \mathrm{~cm}$ ). For S3A Ocean the bias changes randomly and for particular seasons they are out of sync (i.e. in opposite phases) with the other stations, especially from January to March. For the ALES+SAR retracker the bias at most stations (the exception being Narva-Jõesuu station), are synchronized with each other. This is a remarkable improvement compared to the Ocean retracker. This could be due to the retracking algorithm and/or additional corrections (e.g., Radial Orbit correction, refer to Section 4) which was used in the Baltic+SEAL data product. Whilst for Ocean and MLE4 retrackers only the standard corrections are applied. This once more proves that the method made by the ALES+SAR retracker improves the quality of results and the importance of the additional corrections. It should be noted that the bias calculated represents a combination of different corrections and errors associated with the SA results, in order to comply to the corrected HDM results.

With respect to the Jason-3 satellite the MLE4 showed

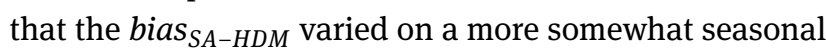
pattern, with a maximum bias $_{S A-H D M}$ of between -26.1 to $31.8 \mathrm{~cm}$ (mean 7.5 to $10.5 \mathrm{~cm}$ ) which is much less than the S3A Ocean retracker. In most cases the bias $s_{S A-H D M}$ at the stations were synchronized, with exceptions in some months. With the JA3 ALES+ retracker the maximum bias of 28.2 to $32.5 \mathrm{~cm}$ (with a mean of 9.3 to $9.6 \mathrm{~cm}$ ), see Fig. 7. With respect to the bias correction, JA3 the ALES+ retracker showed some differences in coherence between two stations. Considering that the JA3-ALES+ provided more data points close to the coast compared to JA3-MLE4 data. Also, once the bias ${ }_{S A-H D M}$ correction is implemented it improves the overall accuracy of the satellite data (Section 5.3).

\subsection{Retrackers Accuracy Assessment}

Once the bias $s_{S A-H D M}$ have been implemented,

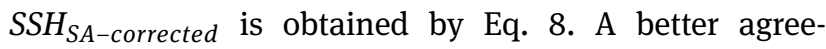
ment between $S_{S H} H_{H M}$ and $S_{S H} H_{S A-c o r r e c t e d}$ was obtained (cf. Fig. 7, Fig. 9). Examination of the yearly RMSE (Eq. 11) amongst all stations is reflected in Table 4. Comparison of the S3A Ocean and ALES+ SAR retrackers shows a slight improvement of the order of approximately of $0.5-1 \mathrm{~cm}$ in terms of RMSE. An accuracy within the range of 4.9-5.5 $\mathrm{cm}$ for the Ocean retracker and 3.9-5.0 cm ALES+ SAR retracker have been achieved. Thus with respect to the JA3 satellite an improvement of $1 \mathrm{~cm}$ is observed with the 

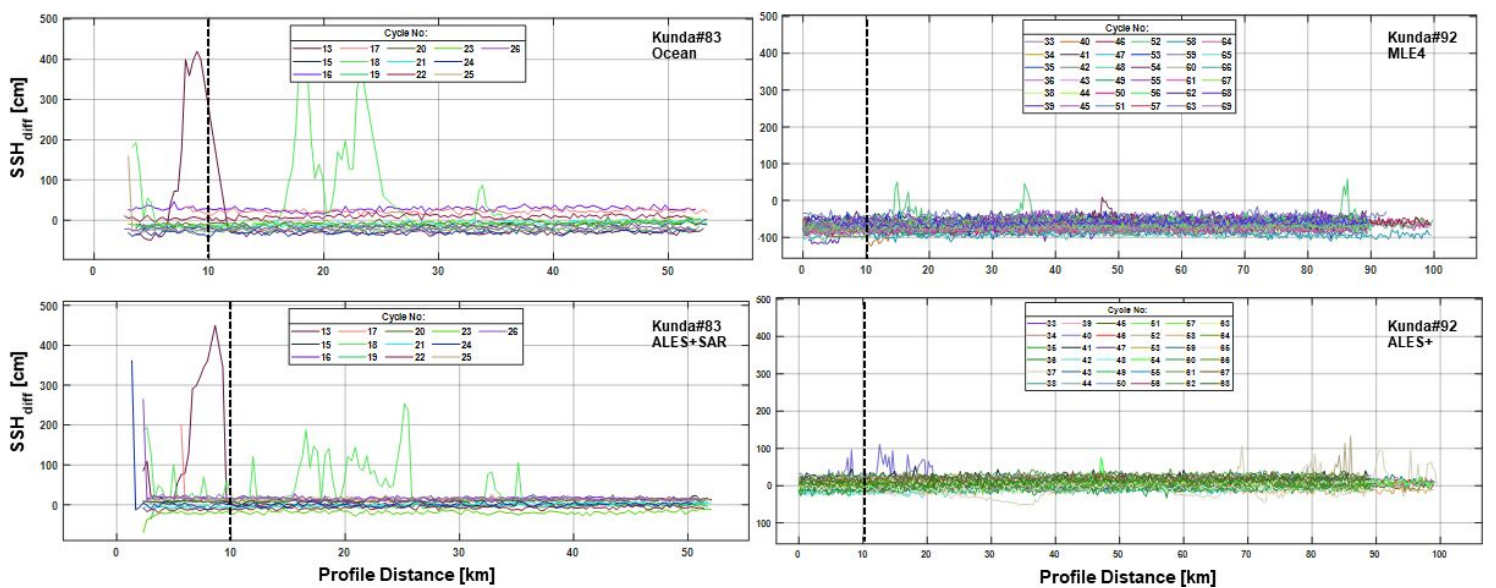

Figure 6: Discrepancies $\mathrm{SSH}_{\text {diff }}$ per each cycle in Kunda-083 S3A (left hand side) and Kunda-092 JA3 (right hand side) using Ocean and MLE4 (top) and ALES+ SAR and ALES+ (bottom) retrackers. The zero value in the horizontal axis denotes the location of the coastline.
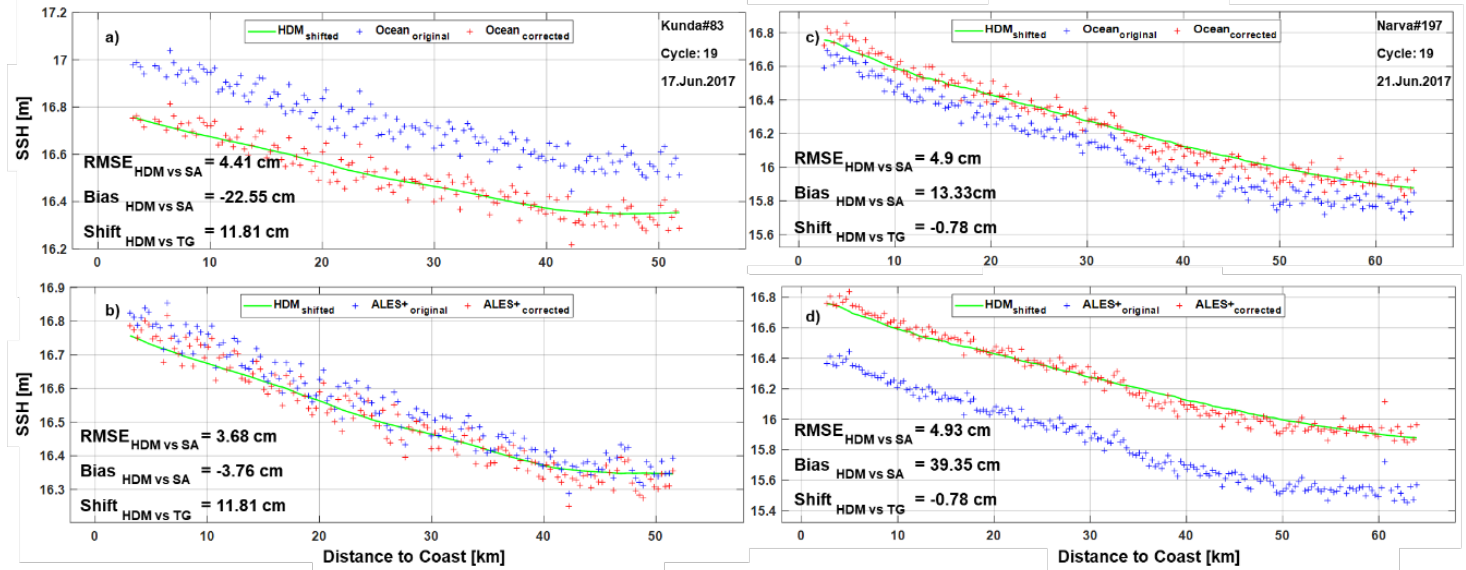

Figure 7: The along track bias per Kunda-083 (a) and Narva-Jõesuu 197 (b) stations in cycle 19 using both Ocean (top) and ALES+ SAR (bottom) retrackers. In this figure red crosses show the SA data points after removing the bias from initial data (blue crosses). The green line represents $H D M_{S S H^{-}}$the ground truth.

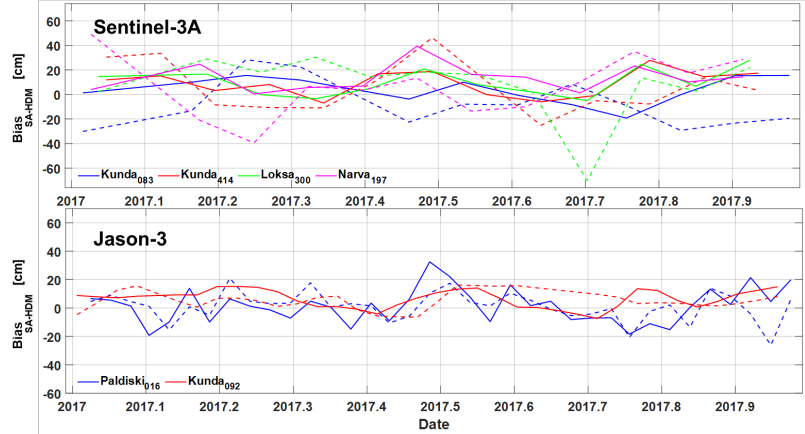

Figure 8: The Sentinel-3A (top) and Jason-3 (bottom) associated bias $_{S A-H D M}$ using standard (dash lines) and ALES+ (lines) retrackers at the used TG station.

ALES+ retracker. The MLE4 retracker had an accuracy of 8.5-7.7 $\mathrm{cm}$ and the ALES+ $6.7-7.4 \mathrm{~cm}$. Overall, the resulting
RMSE was larger for the JA3. These results show that the S3A ALES+ SAR retracker performs the best amongst the examined stations, which meets the required target accuracy of better than $5 \mathrm{~cm}$.

Note that for JA3 satellite a larger number of cycles were considered (35-36 cycles) compared to S3A (12-13 cycles) thus JA3 provide more data points in the gulf along its more inclined track and shorter revisit time (10 days). In the study area S3A provide between 130-190 data points along track for each cycle, whilst JA3 could provide between 200-330 points. The number of data points examined also influences the statistics.

Table 4 shows the yearly RMSEs of SA and HDM derived SSH comparison at each station in 2017 using both Jason-3 and Sentinel-3A datasets after bias $_{S A-H D M}$ removal. Maximum and absolute (abs.) of bias ${ }_{S A-H D M}$ together with number of used cycles at each 
station is also computed. Cycles (e.g. cycles 14 and 18 for Kunda\#083, cycles 14 and 26 for Loksa\#300) with large number of unacceptable outliers were excluded from the calculation from both datasets.

\section{Discussion}

In this study two satellite altimetry missions (Sentinel-3A and Jason-3) using their standard retrackers (Ocean and MLE4, respectively) and a specially improved retracker for the Baltic Sea (ALES+, ALES+ SAR) have been examined in Gulf of Finland. One of the key components of this study is the comparison of the SA data with more realistic ground truth data. This was obtained by incorporating hydrodynamic model (HDM) with tide gauge (TG) data and utilization of a high-resolution geoid model. This method allows us to not only obtain the accuracy of the SA at the coast (not only in the vicinity of the TG) but also to realistically assess the accuracy of data points in offshore via the HDM usage.

First, the performance of the retrackers was explored. The results showed that S3A in SAR mode allows more data points to be consistently obtained closer to the coastline. Obtaining a closeness of 2-3 km from the coastline, as compared to JA3 associated LRM which produces an average distance of 7-10 km. Studies performed in Spain using S3A $80 \mathrm{~Hz}$ data also found that a reliable distance of good quality was reached at a minimum distance of $3 \mathrm{~km}$ (Aldarias et al., 2020). Also a study that compared several retrackers in the archipelagos of Southeast Asia found that the coastal retracker SAMOSA+ performed superior to others within < $2 \mathrm{~km}$ from coastline (Idris et al., 2020). Thus, future studies can also explore the capabilities of SAMOSA+ and the S3A $80 \mathrm{~Hz}$.

With the JA3 ALES+ retracker showed on some occasions the inclusion of more data points closer to the coast especially at the Paldiski station (Fig. 4) and the Finnish coast (to be explored in future studies). Thus, a minimum distance of around $3 \mathrm{~km}$ can be reached on some occasions. In general, the ALES+ and ALES+SAR retracker improved the coherence of both satellite mission's data. Whether, this was due to the additional corrections, for instance the Radial Orbit error that have been corrected with a multi-mission cross calibration or the retracking algorithm utilised, its effect is quite noticeable. It should be noted that JA3 could provide more data points at each track in Gulf of Finland compare to S3A due to the ground track's orientation (Fig. 2). JA3 passes over the gulf with 5 tracks with $\sim 10$ days repeat cycles whilst S3A passes over with 16 tracks and 27 days repeat cycle in the east-westerly elongated shape of the study area.

After the bias $_{S A-H D M}$ correction was applied, the $\triangle S S H$ (Eq. 9) allows an even deeper insight into the performance of SA data source. The results surprisingly show for S3AOcean retracker a bias (mean 18.6-20.7 cm) that varies randomly with time. However, for S3A-ALES+SAR bias magnitude decreases (mean 9.3-13.4 cm) with most stations being synchronized. The Kunda station had different corrections than the other (ascending) tracks, taking into consideration the pass 414 is descending. For JA3 the ALES+ retracker showed a better synchronization than the MLE4 for the examined stations. The magnitude of the bias correction was about the same for the ALES+ (mean 9.3-9.6 cm) and the MLE4 (mean 7.5-10.5 cm). Overall these results emphasize the importance of this bias ${ }_{S A-H D M}$ correction. The bias correction indirectly accounts for any correction that is required to obtain closeness to the true value. The obtained accuracy for S3A "Ocean" products and ALES+SAR achieving a RMSE of 4-5 cm shows better results than previous studies (RMSE of 11.5 and $9.9 \mathrm{~cm}$ in Birgel et al., 2018) in the Gulf of Finland, The results of our study in the Gulf of Finland agree well with that of the Baltic+SEAL validation report (where different stations were examined) for S3A, which obtained a RMSE of 4-7 cm and for the JA3 a RMSE of 7-14 cm (Rautiainen et al., 2020). Thus, in general the study shows promising results that utilization of a method to that incorporates the geoid, HDM and TG along with an improved retracker for the Baltic Sea (ALES+ and ALES+ SAR) enhanced the accuracy of both the S3A and JA3 data.

\section{Conclusion}

Accuracy assessment of two different satellite missions (Sentinel-3A and Jason-3) with their standard retrackers (Ocean and MLE4), and improved retrackers for the Baltic Sea (ALES+, ALES+SAR) is examined in this study. Results show that the ALES+ and ALES+SAR retrackers improves the accuracy of SSH by of the order of $0.5-1 \mathrm{~cm}$ for both missions. With S3A "Ocean" products and ALES+SAR obtaining a root mean square error of 4-5 $\mathrm{cm}$ can be achieved. Whilst with the JA3 ALES+ a root mean square error of 6 $-7 \mathrm{~cm}$ can be achieved. The ALES+ SAR retrackers allowed a consistent distance to the coast of $2-3 \mathrm{~km}$ for S3A whilst a distance of 7-10 km can be mostly achieved with JA3 ALES+ satellite. The developed method in this study incorporates the use of the geoid, tide gauge and hydrodynamic model that allowed the determination of comparable SSH. The method developed in this study can 
Table 4: Statistical estimates of post-fit residuals $\triangle S S H[\mathrm{~cm}]$ for SA and HBM along track SSH for both S3A and JA3 (better performances are emphasised in the bold digits)

\begin{tabular}{cccccccc}
\hline Pass Number & $\begin{array}{c}\text { Max } \\
\text { Bias }\end{array}$ & $\begin{array}{c}\text { Mean } \\
\text { abs. bias }\end{array}$ & RMSE & $\begin{array}{c}\text { Max } \\
\text { Bias }\end{array}$ & $\begin{array}{c}\text { Mean } \\
\text { abs. bias }\end{array}$ & RMSE & $\begin{array}{c}\text { No. } \\
\text { used } \\
\text { cycles }\end{array}$ \\
\hline Sentinel-3A & & Ocean & & & ALES+ SAR & & \\
\hline Kunda\#083 & -30.15 & 18.57 & 4.98 & -19.25 & 9.28 & $\mathbf{4 . 0 5}$ & 12 \\
\hline Kunda\#414 & 46.27 & 16.74 & 5.00 & 27.79 & 11.34 & $\mathbf{3 . 9 5}$ & 13 \\
\hline Loksa\#300 & -70.2 & 19.87 & 4.89 & 28.07 & 11.22 & $\mathbf{4 . 2 5}$ & 12 \\
\hline Narva-Jõesuu \#197 & 49.15 & 20.65 & 5.55 & 39.35 & 13.37 & $\mathbf{5 . 0 4}$ & 11 \\
\hline Jason-3 & & MLE4 & & & ALES+ & & \\
\hline Kunda\#092 & 31.80 & 10.47 & 7.75 & 28.17 & 9.32 & $\mathbf{6 . 7 3}$ & 35 \\
\hline Paldiski\#016 & -26.12 & 7.50 & 8.46 & 32.53 & 9.60 & $\mathbf{7 . 4 0}$ & 36 \\
\hline
\end{tabular}
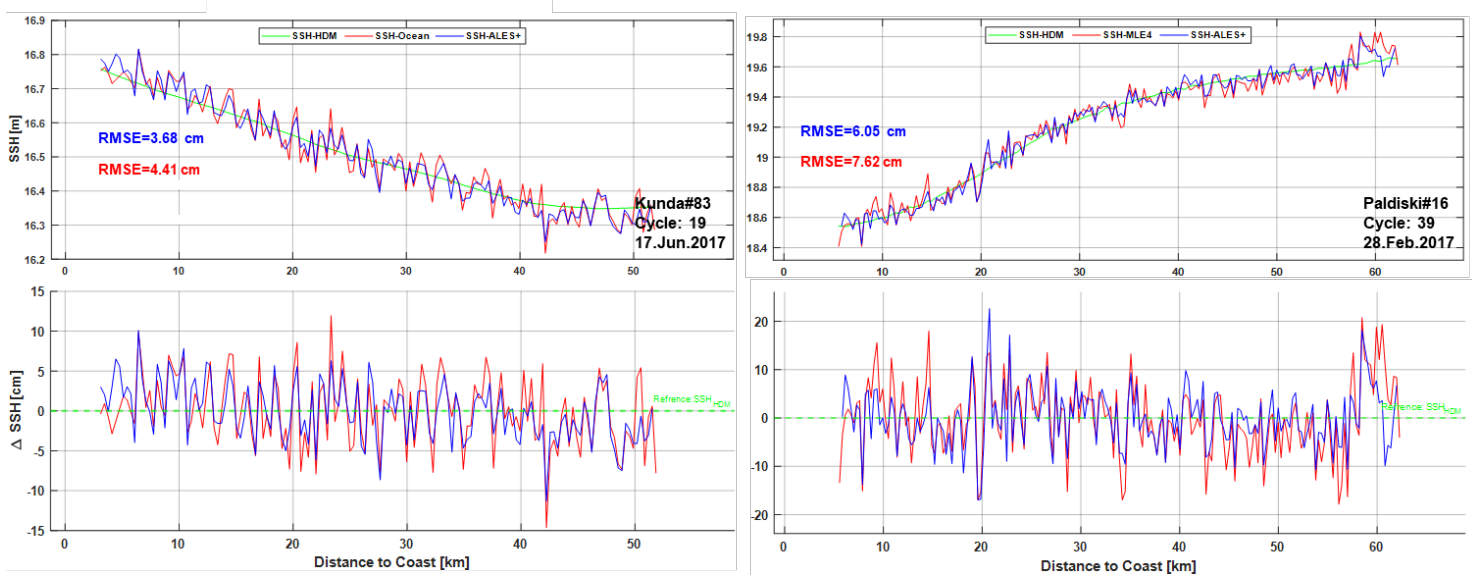

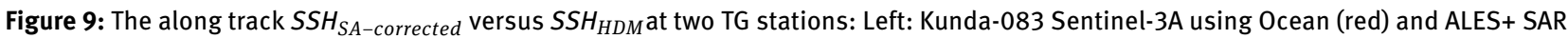
(blue) retrackers Right: Paldiski-016 Jason-3 using MLE4 (red) and ALES+ (blue) retrackers. The bottom plots show differences $\triangle S S H$ between $\mathrm{SSH}_{S A \text {-corrected }}$ and $\mathrm{SSH}_{H D M}$ (green).

be applied for other satellite missions and sea areas that require accurate sea level data.

Authors contribution: M. Mostafavi performed the processing of data, producing the figures and assisted with the writing of the manuscript; N. Delpeche-Ellmann contributed in conceptualization of the idea, analysis of data, supervision and writing of manuscript; A. Ellmann contributed with conceptualization of the idea, supervision, analysis, writing of the paper, providing the resources and funding necessary.

Competing interests: The authors declare that they have no conflict of interest.

Acknowledgements: The research is supported by the Estonian Research Council grants PRG330 'Development of an iterative approach for near-coast marine geoid mod- elling by using re-tracked satellite altimetry, in-situ and modelled data' and PRG1129. The authors are extremely thankful to the Baltic+SEAL project team for granting access to a preliminary version of the dataset. We thank two anonymous reviewers for provided helpful comments on earlier drafts of the manuscript.

\section{References}

Ågren J., Strykowski G., Bilker-Koivula M., Omang O., Märdla S., Forsberg R., Ellmann A., Oja T., Liepiṇš I., Paršeliūnas E., Kaminskis J., Sjöberg L. E., and Valsson G., 2016. The NKG2015 gravimetric geoid model for the Nordic-Baltic region. 1st Joint Commission 2 and IGFS Meeting International Symposium on Gravity, Geoid and Height Systems.

Aldarias A., Gómez-Enri J., Laiz I., Tejedor B., Vignudelli S., and Cipollini P., 2020. Validation of Sentinel-3A SRAL Coastal Sea Level Data at High Posting Rate: 80 Hz. IEEE Trans Geosci Remote Sens. 
58 (6): 3809-3821.

Andersen O. B., Knudsen P., and Berry P. A. M., 2010. The DNSC08GRA global marine gravity field from double retracked satellite altimetry. J. Geod., 84(3), 191-199. https://doi.org/10.1007/s00190009-0355-9

Birgiel E., Ellmann A., and Delpeche-Ellmann N., 2018. Examining the Performance of the Sentinel-3 Coastal Altimetry in the Baltic Sea Using a Regional High-Resolution Geoid Model. Proceedings - 2018 Baltic Geodetic Congress, BGC-Geomatics 2018, 196-201. https://doi.org/10.1109/BGC-Geomatics.2018.00043

Birgiel E., Ellmann A., and Delpeche-Ellmann N., 2019. Performance of sentinel-3A SAR altimetry retrackers: The SAMOSA coastal sea surface heights for the Baltic sea. International Association of Geodesy Symposia, 150, 23-32. https://doi.org/10.1007/1345_2019_59

Bosch W., Dettmering D., and Schwatke C., 2014. MultiMission Cross-Calibration of Satellite Altimeters: Constructing a Long-Term Data Record for Global and Regional Sea Level Change Studies. Remote Sens., 6(3), 2255-2281. https://doi.org/10.3390/rs6032255

Brown G. S., 1977. The Average Impulse Response of a Rough Surface and Its Applications. IEEE Trans. Antennas Propag , 25(1), 67-74. https://doi.org/10.1109/TAP.1977.1141536

Carrere L., Lyard F., Cancet M., Guillot A., Carrere L., Lyard F., Cancet M., and Guillot, A., 2015. FES 2014, a new tidal model on the global ocean with enhanced accuracy in shallow seas and in the Arctic region. EGUGA, 5481. https://ui.adsabs.harvard.edu/abs/ 2015EGUGA..17.5481C/abstract

Cipollini P., Calafat F. M., Jevrejeva S., Melet A., and Prandi P., 2017. Monitoring Sea Level in the Coastal Zone with Satellite Altimetry and Tide Gauges (Vol. 38, pp. 35-59). Springer, Cham. https://doi.org/10.1007/978-3-319-56490-6_3

Delpeche-Ellmann, N., Mingelaitè, T., Soomere, T., 2017. Examining Lagrangian surface transport during a coastal upwelling in the Gulf of Finland, Baltic Sea. Journal of Marine Systems 171, 21-30. https://doi.org/10.1016/j.jmarsys.2016.10.007

Desjonquères J. D., Carayon G., Steunou N., and Lambin J., 2010. Poseidon-3 Radar Altimeter: New Modes and In-Flight Performances. Mar. Geod., 33(sup1), 53-79. https://doi.org/10.1080/01490419.2010.488970

Dinardo S., 2020. Techniques and Applications for Satellite SAR Altimetry over water, land and ice - TUprints. https://doi.org/10.25534/tuprints-00011343

Dinardo S., Bruno L., Ambrózio A., and Jerome B., 2014. SAR Altimetry Processing on Demand Service for CryoSat-2 and Sentinel3 at ESA G-POD. Conference on Big Data from Space (BiDS'14). https://doi.org/10.1109/MGRS.2014.2345997

Ellmann A., Märdla S., and Oja T., 2019. The $5 \mathrm{~mm}$ geoid model for Estonia computed by the least squares modified Stokes's formula. Surv. Rev., 52(373), 352-372. https://doi.org/10.1080/00396265.2019.1583848

Gomez-Enri J., Cipollini P., Passaro M., Vignudelli S., Tejedor B., and Coca J., 2016. Coastal Altimetry Products in the Strait of Gibraltar. IEEE Trans Geosci Remote Sens, 54(9), 5455-5466. https://doi.org/10.1109/TGRS.2016.2565472

Hayne G. S., 1980. Radar Altimeter Mean Return Waveforms from Near-Normal-Incidence Ocean Surface Scattering. IEEE Trans. Antennas Propag, 28(5), 687-692. https://doi.org/10.1109/TAP.1980.1142398.

Idris N.H., Vignudelli S., and Xiaoli D., 2021. Assessment of retracked sea levels from Sentinel-3A Synthetic Aperture Radar (SAR) mode altimetry over the marginal seas at Southeast Asia. Int. J. Remote Sens, 42:4, 1535-1555, DOI: 10.1080/01431161.2020.1836427.

Jahanmard V., Delpeche-Ellmann N., and Ellmann A. Realistic dynamic topography through coupling geoid and hydrodynamic models of the Baltic Sea. Cont. Shelf Res., 222, 104421. https://doi.org/10.1016/j.csr.2021.104421

Jekeli C., 2006. Geometric Reference System in Geodesy. Ohio State University: Columbus, Division of Geodesy and Geospatial Science School of Earth. https://kb.osu.edu/bitstream/handle/ 1811/77986/Geom_Ref_Sys_Geodesy_2016.pdf?sequence $=1 \&$ isAllowed $=y$

Kollo K., and Ellmann A., 2019. Geodetic Reconciliation of Tide Gauge Network in Estonia. Geophysica, 54(1), 27-38. http://www.geophysica.fi/pdf/geophysica_2019_54_kollo.pdf

Lagemaa P., 2012. Operational Forecasting in Estonian Marine Waters. TUT Press, 128.

Lagemaa P., Elken J., and Kõuts T., 2011. Operational sea level forecasting in Estonia. Estonian J. Eng., 17(4), 301-331. https://doi.org/10.3176/eng.2011.4.03

Liibusk A., Kall T., Rikka S., Uiboupin R., Suursaar Ü., and Tseng K.H., (2020). Validation of Copernicus Sea Level Altimetry Products in the Baltic Sea and Estonian Lakes. Remote Sens., 12 (24), 4062. DOI: $10.3390 /$ rs12244062

Märdla S., Ågren J., Strykowski G., Oja T., Ellmann A., Forsberg R., Bilker-Koivula M., Omang O., Paršeliūnas E., Liepinš I., and Kaminskis J., 2017. From Discrete Gravity Survey Data to a High-resolution Gravity Field Representation in the Nordic-Baltic Region. Mar. Geod., 40(6), 416-453. https://doi.org/10.1080/01490419.2017.1326428

Müller F., Dettmering D., Bosch W., and Seitz F., 2017. Monitoring the Arctic Seas: How Satellite Altimetry Can Be Used to Detect Open Water in Sea-Ice Regions. Remote Sens., 9(6), 551. https://doi.org/10.3390/rs9060551

Müller F. L., 2020. User Manual Along-Track Data Baltic+ SEAL Project: ESA AO/1-9172/17/I-BG-BALTIC+ (Sea Level) Internal Dataset 2 (Update).

National Geodetic Survey (NGS)., 2013. The National Geodetic Survey Ten Year Strategic Plan, 2013-2023: Positioning America for the Future. https://www.ngs.noaa.gov/INFO/TenYearPlanpublicreview. pdf

Normandin C., Frappart F., Diepkilé A. T., Marieu V., Mougin E., Blarel F., Lubac B., Braquet N., and Ba A., 2018. Evolution of the Performances of Radar Altimetry Missions from ERS-2 to Sentinel-3A over the Inner Niger Delta. Remote Sens., 10(6), 833. https://doi.org/10.3390/rs10060833

Omstedt A., and Hansson D., 2006. The Baltic Sea ocean climate system memory and response to changes in the water and heat balance components. Cont. Shelf Res., 26(2), 236-251. https://doi.org/10.1016/j.csr.2005.11.003

Passaro M., Cipollini P., Vignudelli S., Quartly G. D., and Snaith H. M, 2014. ALES: A multi-mission adaptive subwaveform retracker for coastal and open ocean altimetry. Remote Sens. Environ., 145, 173-189. https://doi.org/10.1016/j.rse.2014.02.008

Passaro M., Rose S. K., Andersen O. B., Boergens E., Calafat F. M., Dettmering D., and Benveniste J., 2018. ALES+: Adapting a homogenous ocean retracker for satellite altimetry to sea ice leads, coastal and inland waters. Remote Sens. Environ., 211, 456-471. https://doi.org/10.1016/j.rse.2018.02.074

Passaro M., Müller F., and Dettmering D., 2020a. Baltic+ SEAL: 
Algorithm Theoretical Baseline Document (ATBD), Version 2.1. Technical report delivered under the Baltic+ SEAL project. http://doi.org/10.5270/esa.BalticSEAL.ATBDV2.1.

Passaro et al. 2020b. Baltic+ SEAL: Product Handbook, Version X.X. User manual delivered under the Baltic+ SEAL project. [Available in February, 2021].

Rautiainen L., Särkkä J., Tuomi L., Müller F., and Passaro M., 2020. Baltic+ SEAL: Validation Report, Version 2.2 Technical report delivered under the Baltic+ SEAL project. http://doi.org/10.5270/esa.BalticSEAL.VRV2.2

Ray C., Martin-Puig C., Clarizia M. P., Ruffini G., Dinardo S., Gommenginger C., and Benveniste J., 2015. SAR altimeter backscattered waveform model. IEEE Trans Geosci Remote Sens, 53(2), 911919. https://doi.org/10.1109/TGRS.2014.2330423

Roblou L., Lyard F., le Henaff M., and Maraldi C., 2007. X-track, a new processing tool for altimetry in coastal oceans. International Geoscience and Remote Sensing Symposium (IGARSS), 5129-5133. https://doi.org/10.1109/IGARSS.2007.4424016

Roemmich D., Woodworth P., Jevrejeva S., Purkey S., Lankhorst M, Send U, and Nikolai Maximenko N., 2017. In situ observations needed to complement, validate, and interpret satellite altimetry. In Stammer D., and Cazenave A., (Eds.), Satellite altimetry over oceans and land surfaces (pp. 113-148). CRC Press. http://nora.nerc.ac.uk/id/eprint/518392/.

Rulent J., Calafat FM., Banks CJ., Bricheno LM., Gommenginger C., Green JAM., Haigh ID., Lewis H., and Martin ACH., 2020. Comparing Water Level Estimation in Coastal and Shelf Seas From Satellite Altimetry and Numerical Models. Front. Mar. Sci. 7:549467. doi: $10.3389 /$ fmars.2020.549467.
Slobbe D. C., Klees R., and Gunter B. C., 2014. Realization of a consistent set of vertical reference surfaces in coastal areas. J. Geod, 88(6), 601-615. https://doi.org/10.1007/s00190-014-0709-9

Soomere T., Behrens A., Tuomi L., Nielsen JW., 2008. Wave conditions in the Baltic Proper and in the Gulf of Finland during windstorm Gudrun. Nat Hazards Earth Syst. Sci 8(1), 37-46. https://doi.org/10.5194/nhess-8-37-2008

Thibaut P., Labroue S., Ablain M., Faugere Y., and Zanife O.-Z., 2006. Evaluation of the Jason-1 ground retracking algorithm. Ocean Surface Topography Science Team (OSTST) Meeting. https://www.aviso.altimetry.fr/fileadmin/documents/OSTST/ 2006/thibaut.pdf

Thibaut P., Poisson J. C., Bronner E., and Picot N., 2010. Relative Performance of the MLE3 and MLE4 Retracking Algorithms on Jason-2 Altimeter Waveforms. Mar. Geod., 33(sup1), 317-335. https://doi.org/10.1080/01490419.2010.491033

Véronneau M., and Huang J., 2016. The Canadian geodetic vertical datum of 2013 (CGVD2013). Geomatica, 70(1), 9-19. https://doi.org/10.5623/cig2016-101

Vignudelli S., Snaith H. M., Lyard F., Cipollini P., Venuti F., Birol F., Bouffard J., and Roblou L., 2006. Satellite radar altimetry from open ocean to coasts: challenges and perspectives. In Frouin R. J., Agarwal V. K., Kawamura H., Nayak S., and Pan D., (Eds.), Proceedings of 5th Society of Photo-Optical Instrumentation Engineers (SPIE) Asia-Pacific remote sensing symposium (Vol. 6406, pp. 1-12). SPIE Asia-Pacific Remote Sensing. https://doi.org/10.1117/12.694024 